\title{
Large increases in Arctic biogenic volatile emissions are a direct effect of warming
}

Kramshøj, Magnus; Vedel-Petersen, Ida; Schollert, Michelle; Rinnan, Åsmund; Nymand, Josephine; Ro-Poulsen, Helge; Rinnan, Riikka

Published in:

Nature Geoscience

DOI:

10.1038/NGEO2692

Publication date:

2016

Document version

Peer reviewed version

Citation for published version (APA):

Kramshøj, M., Vedel-Petersen, I., Schollert, M., Rinnan, Å., Nymand, J., Ro-Poulsen, H., \& Rinnan, R. (2016).

Large increases in Arctic biogenic volatile emissions are a direct effect of warming. Nature Geoscience, 9(5), 349-352. https://doi.org/10.1038/NGEO2692 


\section{Large increases in arctic biogenic volatile organic compound}

\section{2 emissions are a direct effect of warming}

3 Magnus Kramsh $\varnothing{ }^{1,2}$, Ida Vedel-Petersen ${ }^{1}$, Michelle Schollert ${ }^{1,2}$, Åsmund Rinnan ${ }^{3}$, Josephine

$4 \quad$ Nymand $^{4}$, Helge Ro-Poulsen ${ }^{1,2}$, Riikka Rinnan ${ }^{1,2}$

$6{ }^{1}$ Terrestrial Ecology Section, Dept. of Biology, University of Copenhagen, Universitetsparken 15,

7 Building 1, DK-2100 Copenhagen $\varnothing$, Denmark

$8{ }^{2}$ Center for Permafrost (CENPERM), Dept. of Geography and Geology, University of Copenhagen,

9 Øster Voldgade 10, DK-1350 Copenhagen K, Denmark

$10{ }^{3}$ Spectroscopy \& Chemometrics Section, Dept. of Food Science, University of Copenhagen,

11 Rolighedsvej 26, DK-1958 Frederiksberg C, Denmark

$12{ }^{4}$ Greenland Institute of Natural Resources, Kivioq 2, DK-3900, Nuuk, Greenland 
Biogenic volatile organic compounds are reactive gases that can contribute to atmospheric aerosol formation ${ }^{1}$. Their emission from vegetation is dependent on temperature and light availability $^{2}$. Increasing temperature, changing cloud cover, and shifting composition of vegetation communities can be expected to affect emissions in the Arctic, where the ongoing climate changes are particularly severe ${ }^{3}$. Here we present biogenic volatile organic compound emission data from arctic tundra exposed to six years of experimental warming or reduced sunlight treatment in a randomized block design. By separately assessing the emission response of the whole ecosystem, plant shoots and soil in four measurements covering the growing season, we have identified that warming increased the emissions directly rather than via a change in the plant biomass and species composition. Warming caused a $260 \%$ increase in total emission rate for the ecosystem and a $90 \%$ increase in emission rates for plants, while having no effect on soil emissions. Compared to the control, reduced sunlight decreased emissions by $69 \%$ for the ecosystem, 61-65\% for plants and $78 \%$ for soil. The detected strong emission response is considerably higher than observed at more southern latitudes, emphasizing the high temperature sensitivity of ecosystem processes in the changing Arctic. All organisms release VOCs for a range of physiological and ecological reasons, but the majority of emissions is derived from vegetation ${ }^{2}$. When low-volatile BVOC oxidation products condensate onto aerosol surfaces, it enhances the formation and growth of secondary organic aerosols ${ }^{4}$. The emission of BVOCs therefore indirectly affects the Earth's radiation balance, as secondary organic aerosols scatter solar radiation and act as cloud condensation nuclei, leading to enhanced albedo 5 .

BVOC emission rates in general peak in the tropics and then decrease towards the poles $^{6}$. In the Arctic, models have assumed minimal emissions due to low temperatures, short growing seasons and sparse vegetation cover ${ }^{6,7}$. However, recent field studies indicate that 
emissions from arctic tundra greatly exceed estimates based upon models relying on ambient air temperatures rather than canopy temperatures ${ }^{8,9}$, which are strongly decoupled from air temperature due to the low-stature canopy and adaptations of arctic plants ensuring maximal trapping of heat to warm the canopy ${ }^{10,11}$.

Light is needed for photosynthesis, and BVOCs like isoprene that are directly released upon biosynthesis are emitted light-dependently ${ }^{12}$. The production and diffusion rates of BVOCs correlate with temperature, with typical exponential response curves ${ }^{12}$. Direct solar radiation has especially large influence on leaf temperatures in low canopy vegetation ${ }^{11}$, such as tundra, and changes in cloud cover could thus indirectly have a large impact on emission rates.

While the effect of changes in light availability has hardly been considered, long term field studies suggest that BVOC emission response to experimental warming is much larger in high latitude compared to other ecosystems ${ }^{13-16}$, indicating that the effect of climate changes on BVOC emission is dependent on the type and state of the ecosystem ${ }^{16}$. A potential reason for the large temperature response in high latitude systems is that the increased BVOC emission is an indirect result of temperature-driven plant biomass increase in these temperature-limited ecosystems ${ }^{13}$. The ongoing warming of the Arctic has led to increased plant biomass and altered species composition in the tundra ${ }^{17}$, and experimental warming studies indicate that the biomass increase is linear over time $^{18}$. In order to identify the mechanisms behind the large emission responses observed in the Arctic, we assessed the effects of warming (W) and reduced sunlight (RS) on BVOC emissions from arctic tundra separately for the whole ecosystem, dominant plants and soil. We examined the responses to elevated temperature using Plexiglas open top chambers, which increase air temperature by $2-3{ }^{\circ} \mathrm{C}$, and to RS using dome-shaped hessian tents, which decrease photosynthetically active radiation (PAR) by $65 \%$, in dry dwarf-shrub tundra in Western Greenland 
$\left(64^{\circ} 07^{\prime} \mathrm{N}, 51^{\circ} 21^{\prime} \mathrm{W}\right)$. The experiment had six replicate plots for each treatment. The vegetation was homogeneous and co-dominated by the crowberry Empetrum hermaphroditum and grey willow Salix glauca (Supplementary Table S1) with occasional spots of bare soil. Both plant species are common dwarf shrubs with a circumboreal-polar distribution.

The BVOC emissions were estimated using enclosure technique and collection of the emitted volatiles in adsorbent cartridges, which were analyzed by gas chromatography-mass spectrometry (see Methods). The ecosystem emissions were measured by enclosing whole ecosystem plots $(33 \times 33 \mathrm{~cm})$ including intact vegetation and the underlain soil. The plant measurements were made on enclosed shoots of E. hermaphroditum and S. glauca, and the soil measurements were made on enclosed bare soil spots.

The unmanipulated heath proved to be a significant source of BVOCs having a daytime emission rate of $338 \mu \mathrm{g} \mathrm{m}^{-2}$ ground area $\mathrm{h}^{-1}$ averaged across the season (Fig. 1a). Isoprene, which was primarily emitted by $S$. glauca, dominated the emission profile constituting $87 \%$ of the total emission (Supplementary Tables S1 and S2). Non-terpenoid compounds accounted for $7 \%$ of the total emission, while sesquiterpenes and monoterpenes, primarily emitted by $E$. hermaphroditum (Supplementary Table S1 and S3), accounted for 5\% and 1\%, respectively. Across the season, the ecosystem BVOC emission was consistently higher from $\mathrm{W}$ and lower from the RS treatment compared to the control (Fig. 1a).

$\mathrm{W}$ increased the enclosure temperature by $3.1{ }^{\circ} \mathrm{C}$ averaged over all measurements (Supplementary Table S2), but it also decreased soil moisture from $22.0 \%$ in control to $17.8 \%$ in W (Supplementary Table S3). This decrease in soil moisture in response to warming is well in agreement with the projected changes in soil moisture under climate change ${ }^{19}$. The aboveground plant biomass was lower in both RS and W compared to the control (Supplementary Table 3S), and in order to not let this difference interact with the assessment of treatment effects on the emissions, 
we proportioned the ecosystem emission to the estimated aboveground plant biomass in each plot (see Methods). The decrease in aboveground plant biomass in $\mathrm{W}$ was in line with earlier findings from water limited arctic ecosystems ${ }^{17,18}$, and was likely due to amplified drought stress in the W plots $^{11}$.

(1)

$260 \%$ in W compared to the control (Fig. 2a). This temperature relationship corresponds to a Q10 of 22, in which Q10 describes the factor by which the emission rate increases with a $10{ }^{\circ} \mathrm{C}$ rise in temperature. The high Q10 highlights the extreme temperature sensitivity of BVOC emissions from arctic tundra relative to other processes affected by warming; for example, the Q10 for BVOC emissions is typically between 3-6 (ref. 16), and that for biological processes in general is around 2.5 (ref. 20).

7

The ecosystem BVOC emission increase was primarily driven by isoprene and nonterpenoid compounds, increasing $240 \%$ and $590 \%$ compared to the control, respectively (Fig. 2a). The monoterpene and sesquiterpene emission response to warming was substantial but less profound, with $140 \%$ and $60 \%$ increases in emissions, respectively. The effect of warming was much greater than expected based on the parameterizations used in models applying exponential relationships between emission rate and temperature ${ }^{21}$ and more drastic than the increase documented for a subarctic heath ${ }^{14,22}$. Furthermore, the effect was a consequence of direct stimulation of biosynthesis, rather than a result of higher plant biomass due to warming ${ }^{13}$. The large response to warming may be linked to the effects of decreased soil moisture, which is a key driver of vegetation properties in arctic-alpine ecosystems ${ }^{23}$. Moderate drought stress has in some cases increased isoprene emissions ${ }^{15,16}$, possibly by limiting the naturally cooling evapotranspiration process, resulting in higher leaf temperatures ${ }^{11}$. 
110 (Supplementary Table S2) and soil temperature by $0.5^{\circ} \mathrm{C}$ (Supplementary Table S3). Corrected for 111 plant biomass, the total BVOC emission from RS was $69 \%$ lower than the control, mainly due to 112 lower isoprene emissions (Fig. 2a). The decrease may be explained by the reduced temperature and 113 probably to a higher extent by the light dependency of the emission of isoprene that is released upon 114 synthesis, and thus coupled to photosynthesis ${ }^{21,25}$. The treatment responses in the plant shoot BVOC emissions were in agreement with the responses at the ecosystem level. Compared to the control, the total BVOC emissions from $S$. glauca and E. hermaphroditum increased with $90 \%$ in W, and decreased with 61-65\% in RS (Fig. $2 \mathrm{~b}$ and 2c). S. glauca had an average emission rate of $7.8 \mu \mathrm{g} \mathrm{g}^{-1} \mathrm{dw}$ leaf biomass $\mathrm{h}^{-1}$ with isoprene accounting for $85 \%$ of the total emission (Fig. 2b). The average emission rate of E. hermaphroditum was $2.6 \mu \mathrm{g} \mathrm{g}^{-1} \mathrm{dw}$ leaf biomass $\mathrm{h}^{-1}$, mainly consisting of sesquiterpenes and non-terpenoid compounds (Fig. 2c).

In general, the emissions from bare soil proved to be substantial, constituting $20 \%$ of the total BVOCs released from the whole ecosystem measurements. Total soil BVOC emission rate was $59.1 \mu \mathrm{g} \mathrm{m}^{-2} \mathrm{~h}^{-1}$, with non-terpenoid compounds accounting for $95 \%$. The seasonal variation in soil and plant emissions is shown in Supplementary Figure S1, and complete lists of compounds emitted are shown in Supplementary Tables S4-S7. the negative response observed also in the plant and ecosystem measurements. However, in contrast to the stimulation of plant and ecosystem emissions, W had no effects on the soil emissions (Fig. 2d). The decrease in soil emissions by RS cannot be fully explained by abiotic factors since soil temperature at $3-5 \mathrm{~cm}$ depth only decreased by $0.5^{\circ} \mathrm{C}$ (Supplementary Table S3), and solar radiation only directly affects the soil surface. Instead, we suggest that root biomass played a role. 
The majority of BVOCs released from soil derive from the rhizosphere including emissions from

134 roots, rhizospheric bacteria and fungi ${ }^{26}$. Reduced light availability increases allocation of resources

135 to stem and leaves at the expense of roots ${ }^{27}$ suggesting reduced biomass and thereby lower root-

136 derived emissions in the RS treatment. Also the decrease in aboveground plant biomass in RS

137 (Supplementary Table S3) has probably been accompanied by a decrease in root biomass. Results

138 from an earlier long term warming experiment in arctic tundra indicate that belowground plant

139 biomass is unaffected by open top chamber warming, which could explain the lacking soil emission

140 response to warming in our study ${ }^{28}$.

To assess which biological or environmental factors affect the ecosystem-level BVOC

emissions, we conducted a partial least squares (PLS) regression ${ }^{29}$ analysis on the ecosystem

emission of the dominant BVOC, isoprene. Isoprene emission correlated positively with net ecosystem exchange, the biomass of $S$. glauca, a strong isoprene emitter ${ }^{2}$, and PAR (Fig. 3) which is in agreement with the well-established light dependence of isoprene emission ${ }^{12}$. In contrast, several soil-related, inter-correlated, variables had a negative relationship with ecosystem isoprene emission (Fig. 3). The most influential of these variables were ecosystem respiration, soil microbial biomass carbon and bacterial abundance (number of $16 \mathrm{~S}$ rDNA copies). We hypothesize that the negative relationship demonstrates active soil bacterial uptake of isoprene in the ecosystem ${ }^{30}$. The responses of this process to climate change and the importance to the ecosystem net emissions remain to be untangled.

Our results demonstrate several-fold increased BVOC emission from a dry arctic

$154 \mathrm{Arctic}^{3}$. The drastic increase is in agreement, but cannot be fully explained by increases in emissions per gram leaf biomass of the dominant plant species. The unexplained emission increase may be due to strong temperature dependency in BVOC emission from mosses, lichens, 
decomposing litter and subdominant vascular plants in the whole ecosystem plots (Supplementary Table S1). Reduced sunlight decreased emission rates both from plants, soil, and the whole ecosystem, probably due to both reduced light availability per se and surface cooling. under climate change. Since 1979 , arctic land surface has warmed at a rate of $0.5^{\circ} \mathrm{C}$ per decade and in 2100 temperatures in the Arctic are projected to have increased by $2-8{ }^{\circ} \mathrm{C}$ (ref. 3 ). In remote areas, such as the Arctic, where the air is clean, the growth of particles large enough to act as cloud condensation nuclei, is tightly coupled to the emission of BVOCs ${ }^{1}$, and warming-induced emissions in the Arctic may therefore lead to increased cloud formation. As BVOC emissions are highly regulated by sunlight availability, the warming-induced emissions might in fact initiate a negative feedback mechanism between the biosphere, aerosols and climate.

\section{Additional Information}

171 The processed data for this manuscript can be found in the Figshare database

172 (http://figshare.com/authors/Magnus_Kramsh_j/830572). 
182 1. Paasonen, P. et al. Warming-induced increase in aerosol number concentration likely to moderate climate change. Nat. Geosci. 6, 438-442 (2013).

2. Laothawornkitkul, J., Taylor, J. E., Paul, N. D. \& Hewitt, C. N. Biogenic volatile organic 185 compounds in the Earth system: Tansley review. New Phytol. 183, 27-51 (2009).

3. IPCC, 2013: Climate Change 2013: The Physical Science Basis. Contribution of Working Group I to the Fifth Assessment Report of the Intergovernmental Panel on Climate Change [Stocker, T. F., Qin, D., Plattner, G.-K., Tignor, M. M. B., Allen, S. K., Boschung, J., Nauels, A., Xia, Y., Bex, V. \& Midgley, P. M. (eds.)]. Cambridge University Press, Cambridge, United Kingdom and New York, NY, USA, 1535 pp. at <http://www.climatechange2013.org/>

4. Smith, S. J., Edmonds, J., Hartin, C. A., Mundra, A. \& Calvin, K. Near-term acceleration in 193 the rate of temperature change. Nature Clim. Change 5, 333-336 (2015).

5. Carslaw, K. S. et al. Atmospheric aerosols in the earth system: a review of interactions and feedbacks. Atmos. Chem. Phys. 9, 11087-11183 (2009). Geosci. Model Dev. 5, 1471-1492 (2012).

7. Grote, R. \& Niinemets, Ü. Modeling volatile isoprenoid emissions - A story with split ends. Plant Biol. 10, 8-28 (2008). 
201 8. Holst, T. et al. BVOC ecosystem flux measurements at a high latitude wetland site. Atmos. Chem. Phys. 10, 1617-1634 (2010).

9. Potosnak, M. J. et al. Isoprene emissions from a tundra ecosystem. Biogeosciences 10, 871889 (2013).

10. Rinnan, R., Steinke, M., McGenity, T. \& Loreto, F. Plant volatiles in extreme terrestrial and marine environments. Plant Cell Environ. 37, 1776-1789 (2014).

11. Körner, C. in Plant Growth and Climate Change (eds. Morison, J. I. L. \& Morecroft, M.) 4869 (Blackwell Publishing Ltd, 2007). doi:10.1002/9780470988695.ch3

12. Niinemets, Ü., Loreto, F. \& Reichstein, M. Physiological and physicochemical controls on foliar volatile organic compound emissions. Trends Plant Sci. 9, 180-186 (2004).

211 13. Valolahti, H., Kivimäenpää, M., Faubert, P., Michelsen, A. \& Rinnan, R. Climate changeinduced vegetation change as a driver of increased subarctic biogenic volatile organic compound emissions. Glob. Change Biol. (2015). doi:10.1111/gcb.12953

214 14. Faubert, P. et al. Doubled volatile organic compound emissions from subarctic tundra under simulated climate warming. New Phytol. 187, 199-208 (2010).

216 15. Monson, R. K. et al. Isoprene emission from terrestrial ecosystems in response to global change: minding the gap between models and observations. Phil. Trans. R. Soc. A 365, 1677-1695 (2007). 
220 17. Elmendorf, S. C. et al. Plot-scale evidence of tundra vegetation change and links to recent summer warming. Nature Clim. Change 2, 453-457 (2012).

18. Elmendorf, S. C. et al. Global assessment of experimental climate warming on tundra vegetation: Heterogeneity over space and time. Ecol. Lett. 15, 164-175 (2012).

19. AMAP, 2011. Snow, Water, Ice and Permafrost in the Arctic (SWIPA): Climate Change and

20. Niinemets, Ü. in Advances in Plant Physiology (ed. Hemantaranjan, A.) 233-268 (Scientific Publishers, 2004)

21. Guenther, A. B., Zimmerman, P. R., Harley, P. C., Monson, R. K. \& Fall, R. Isoprene and monoterpene emission rate variability: Model evaluations and sensitivity analyses. $J$. Geophys. Res. 98, 12609-12617 (1993).

22. Tiiva, P. et al. Climatic warming increases isoprene emission from a subarctic heath. New

23. Le Roux, P. C., Aalto, J. \& Luoto, M. Soil moisture's underestimated role in climate change impact modelling in low-energy systems. Glob. Change Biol. 19, 2965-2975 (2013).

24. Dani, S., Jamie, I. M., Prentice, I. C. \& Atwell, B. J. Increased ratio of electron transport to net assimilation rate supports elevated isoprenoid emission rate in eucalyptus under drought. Plant Physiol. 166, 1059-1072 (2014). 
25. Loreto, F. \& Schnitzler, J.-P. Abiotic stresses and induced BVOCs. Trends Plant Sci. 15, 154-166 (2010).

26. Peñuelas, J. et al. Biogenic volatile emissions from the soil. Plant Cell Environ. 37, 1866$1891(2014)$.

27. Poorter, H. et al. Biomass allocation to leaves, stems and roots: Meta-analyses of interspecific variation and environmental control. New Phytol. 193, 30-50 (2012).

28. Rinnan, R., Michelsen, A., Bååth, E. \& Jonasson, S. Fifteen years of climate change manipulations alter soil microbial communities in a subarctic heath ecosystem. Glob. Change Biol. 13, 28-39 (2007).

29. Geladi, P. \& Kowalski, B. R. Partial least-squares regression: A tutorial. Anal. Chim. Acta 185, 1-17 (1986).

30. Cleveland, C. C. \& Yavitt, J. B. Microbial Consumption of atmospheric isoprene in soil. Geophys. Res. Lett. 24, 2379-2382 (1997). 
259 Correspondence and requests for materials should be addressed to Riikka Rinnan:

260 riikkar@bio.ku.dk

\section{Acknowledgements}

263 We thank Mathilde Borg Dahl, Peter Cornelius Brusvang and Merian Skouw Haugwitz for sharing 264 excellent and invaluable datasets and Guy Schurgers and Christian Albers for constructive criticism 265 and useful suggestions for the manuscript.

We also thank Villum foundation, the Danish Council for Independent Research |

267 Natural Sciences, and the Carlsberg foundation for funding the project. The Danish National

268 Research Foundation supported the activities within the Center for Permafrost (CENPERM

269 DNRF100). Pinngortitaleriffik - Greenland Institute of Natural Resources and Greenland 270 Ecosystem Monitoring Programme provided an excellent logistical basis for the work. Data from 271 the Greenland Ecosystem Monitoring Programme were provided by the Department of Bioscience, 272 Aarhus University, Denmark in collaboration with Greenland Institute of Natural Resources, Nuuk, 273 Greenland, and Department of Biology, University of Copenhagen, Denmark.

275 Author Contributions

276 MK and IVP collected the data. MK, IVP, MS and RR analyzed and interpreted the dataset. ÅR 277 performed the PLS analysis. JN and HRP established the experimental site. MK wrote the 278 manuscript with contributions from all authors.

280 Author Information

281 The authors declare no competing financial interests. 
a Ecosystem emission

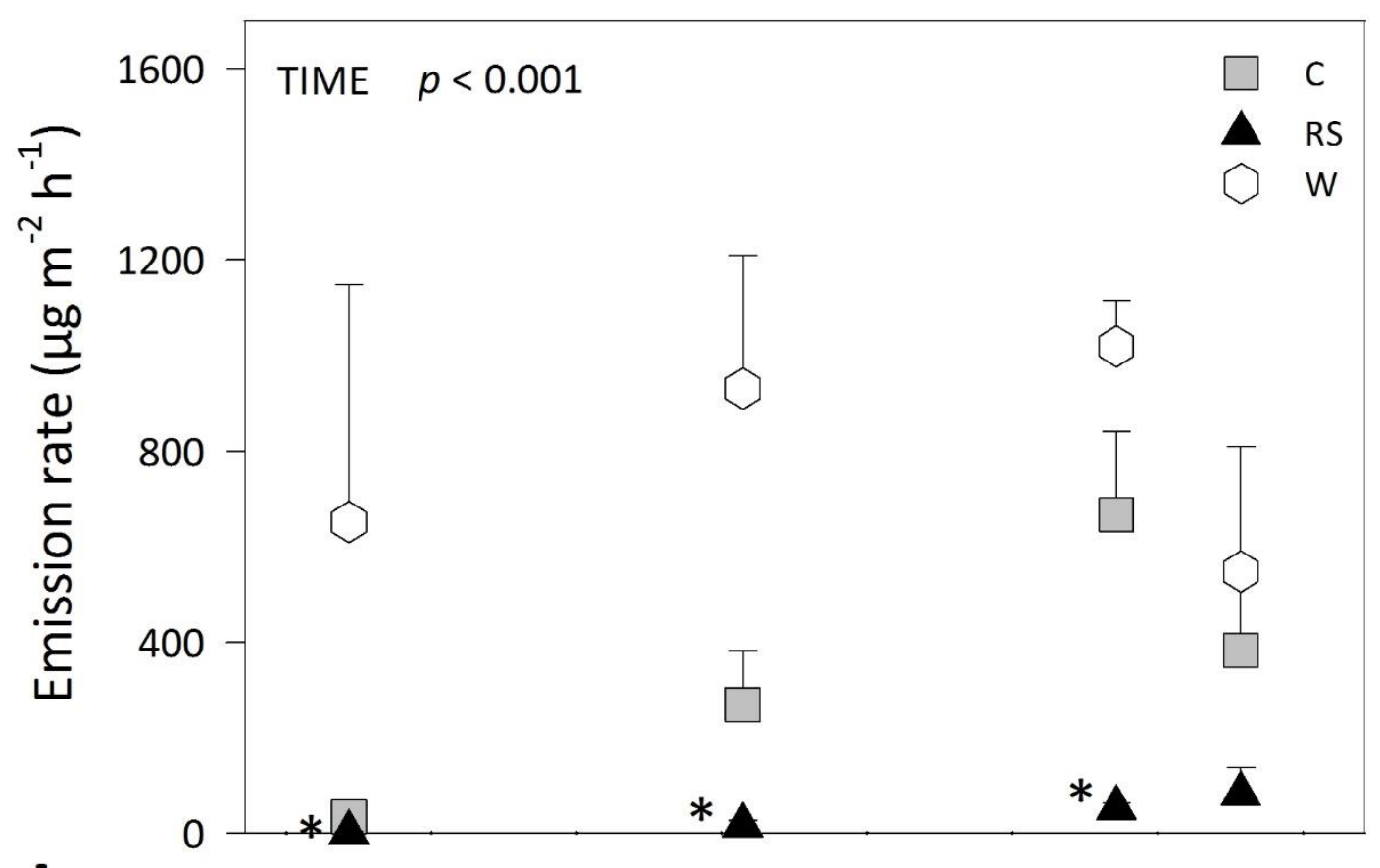

b

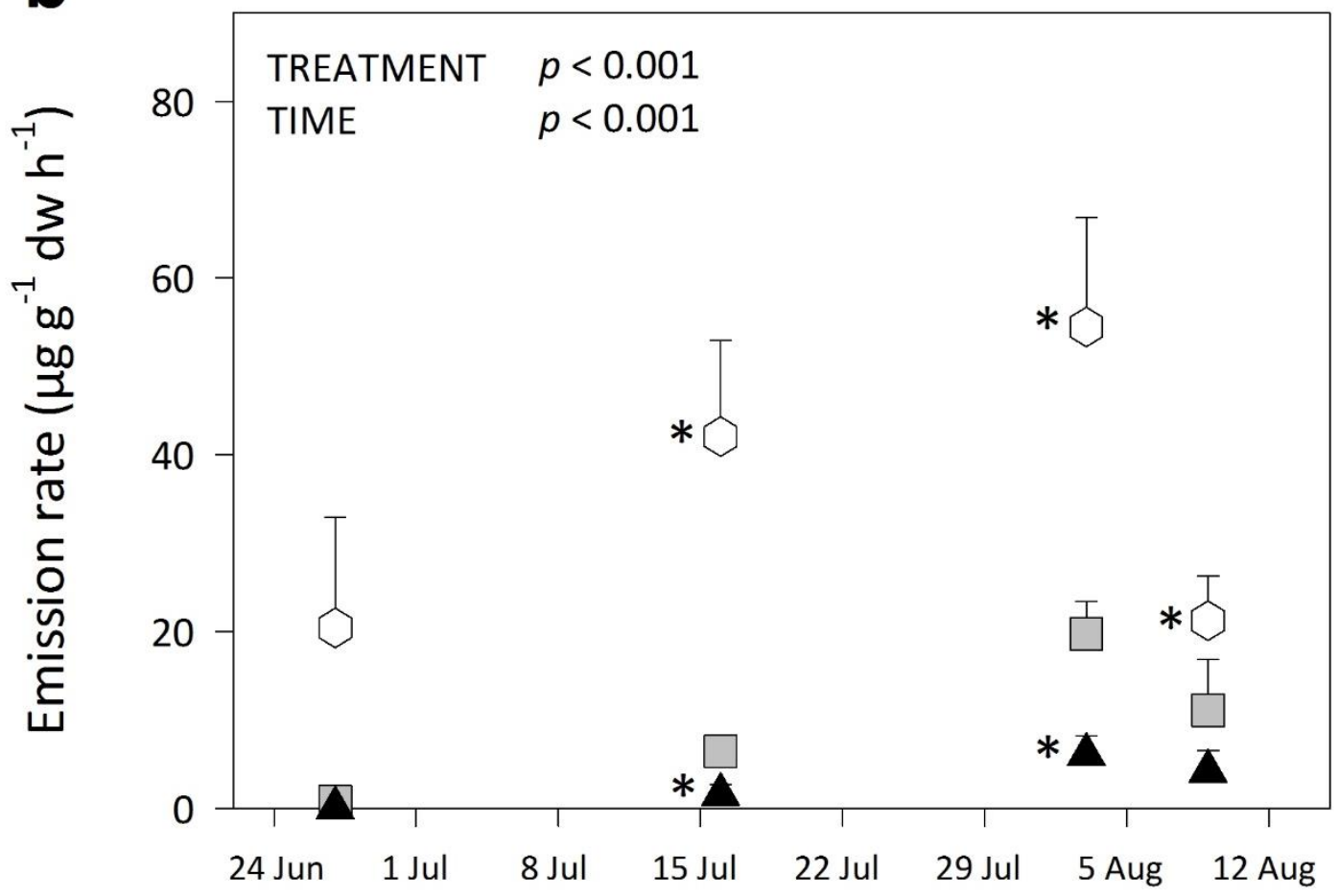

284 Figure 1: Biogenic volatile organic compound emission across the season. a, Mean emission

285 rate $(n=5)$ per ground area and $\mathbf{b}$, mean emission rate $(n=5)$ per dry weight plant biomass.

286 Statistically significant $p$-values for the repeated measures ANOVA are shown. Asterisks signify 
statistically significant difference from the control within the measurement dates (Dunnett's test, $* p$

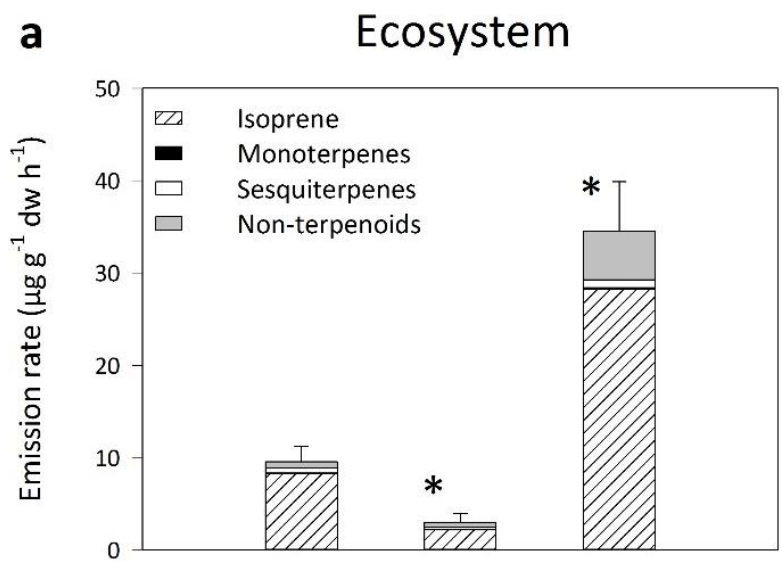

Salix

b

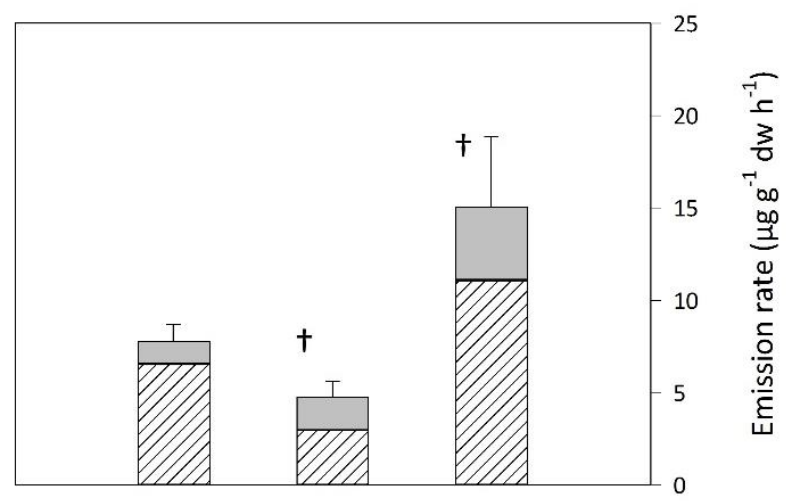

C

Empetrum

Soil

d
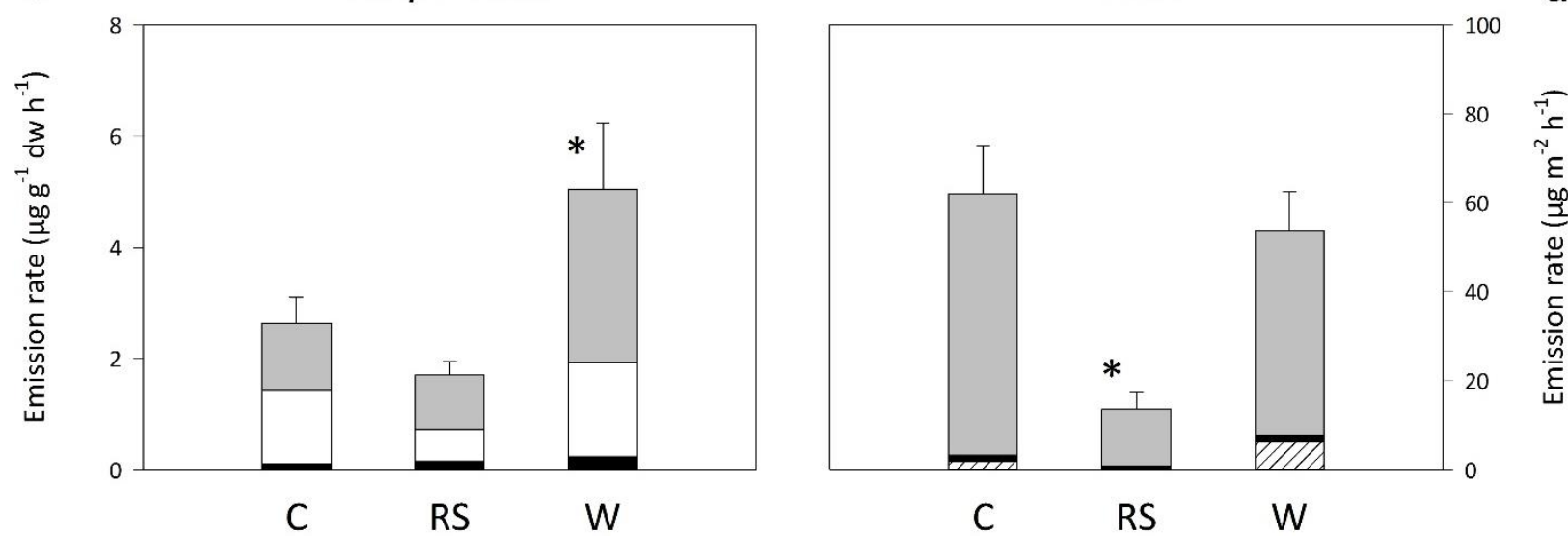

Figure 2: Growing season average of biogenic volatile organic compound emission. a,

Emission from whole ecosystem corrected for plant biomass $(n=5) \mathbf{b}$, Emission from Salix glauca $(n=6)$ c, Emission from Empetrum hermaphroditum $(n=6)$ and d, Emission from soil $(n=6)$. The division of the total emissions to isoprene, monoterpenes, sesquiterpenes and non-terpenoids is shown. Symbols signify statistically significant difference compared to control (Mixed model, Dunnett's test, $* p<0.05 ; \dagger p<0.1)$. Error bars represent standard error of the mean. 


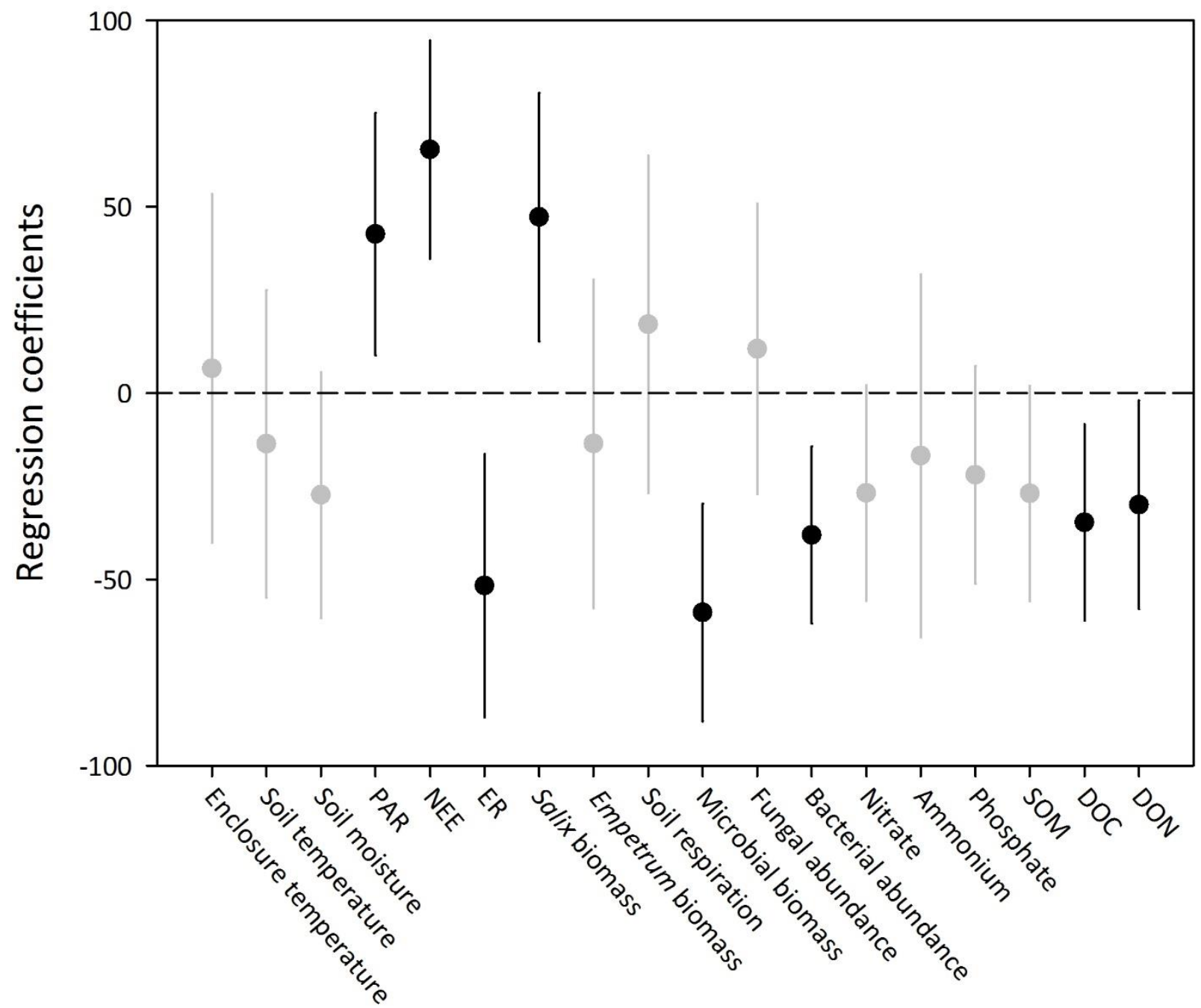

Figure 3: Correlation between measured background variables and isoprene emission for the

tundra ecosystem. Average regression coefficients for the partial least squares regression on isoprene emission. The error bars show $1.96 \times$ standard error calculated from 1000 bootstrap samples. Significant factors are shown in black. PAR, photosynthetically active radiation; NEE, net ecosystem exchange; ER, ecosystem respiration; SOM, soil organic matter; DOC, dissolved organic carbon; DON, dissolved organic nitrogen. 
Methods

\section{Study site and experimental setup}

The data were collected during the growing season of 2013 in Kobbefjord, $20 \mathrm{~km}$ southeast of

311 Nuuk, Greenland $\left(64^{\circ} 07^{\prime} \mathrm{N}, 51^{\circ} 21^{\prime} \mathrm{W}\right)$. The experiment that was initiated in 2007 (ref. 31 ) spanned approx. 50 x $100 \mathrm{~m}$ and consisted of 18 hexagon-shaped plots (diameter $1.2 \mathrm{~m}$ ). Control plots and the treatments $\mathrm{W}$ and RS were distributed to the experiment in randomized complete block design

$314(n=6)$. One block was excluded from the "whole ecosystem" measurements, because the vegetation composition in this block differed from the other blocks. It did not have any Salix glauca, which was one of the two dominant species in the studied tundra $(n=5)$.

\section{Sampling of BVOCs}

319 Plant and soil BVOC emission was measured using a dynamic headspace sampling technique, while ecosystem emission was measured using a push-pull enclosure technique ${ }^{13,32}$. Air was circulated through the systems by battery-operated pumps connected via Teflon tubes. The incoming air was purified by an activated charcoal filter to remove particles and VOCs, and by a $\mathrm{MnO}_{2}$ scrubber to were sealed with Teflon-coated brass caps, and stored refrigerated until analysis. The used adsorbent cartridges capture compounds in the range C5-C30. Using this method a number of oxygenated BVOCs might not be captured quantitatively.

We used precleaned $\left(120^{\circ} \mathrm{C}\right.$ for $1 \mathrm{hr}$.) disposable polyethylene terephthalate (PET) bags that were attached to a polyvinyl chloride (PVC) cylinder (diameter $10 \mathrm{~cm}$ ) installed in bare 
soil or around a shoot of S. glauca or E. hermaphroditum, for soil and plant enclosures, respectively. The adsorbent cartridge was inserted into the PET bag through a hole cut in the corner, which was afterwards tightly closed with plastic-coated wire. Prior to each measurement, the bags were ventilated for five minutes with an inflow rate of $1000 \mathrm{ml} \mathrm{min}^{-1}$, and during measurements the

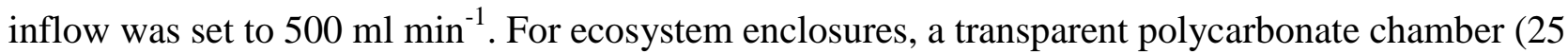
L; Vink Finland, Kerava, Finland), equipped with a fan to ensure well-mixed headspace, was placed on the permanent chamber base in each plot. The cartridge was mounted directly on the chamber and the inflow rate was set to $215 \mathrm{ml} \mathrm{min}^{-1}$.

Blank samples were collected to account for VOCs released from sampling materials or analysis system. During all measurements, shaded iButtons (Hygrochron, Maxim Integrated, San Jose, USA) placed inside the enclosure logged temperature and relative humidity once per minute. PAR was monitored in each treatment using S-LIA-M003 sensors connected to a HOBO micro station data logger (H21-002, Onset computers corporation, Boston, USA).

\section{Analysis of BVOCs}

The BVOC samples were analyzed by a gas chromatograph-mass spectrometer (7890A Series GC coupled with a 5975C inert MSD/DS Performance Turbo EI System, Agilent, Santa Clara, CA, $0.33 \mu \mathrm{m})$.

BVOCs were identified using pure standards and according to their mass spectra in USA) after thermal desorption (UNITY2 coupled with an ULTRA autosampler, Markes, Llantrisant, UK). The carrier gas was helium and oven temperature was held at $40{ }^{\circ} \mathrm{C}$ for $1 \mathrm{~min}$, then raised to $210{ }^{\circ} \mathrm{C}$ at a rate of $5^{\circ} \mathrm{C} \mathrm{min}^{-1}$, and finally further to $250{ }^{\circ} \mathrm{C}$ at a rate of $20{ }^{\circ} \mathrm{C} \mathrm{min}{ }^{-1}$. BVOCs were separated using an HP-5 capillary column $(50 \mathrm{~m}$, diameter $0.2 \mathrm{~mm}$, film thickness $0.33 \mu \mathrm{m})$. 
Table S8 for a list of compounds). Standard solutions were injected into adsorbent cartridges in a stream of Helium and analyzed as samples. When quantifying compounds for which no pure standard was available, $\alpha$-pinene was used for monoterpenes, humulene was used for sesquiterpenes and toluene was used for non-terpenoids. Compounds were classified into one of following four groups: isoprene, monoterpenes, sesquiterpenes and non-terpenoids. ground area basis, and ecosystem emissions both on ground area basis and per dry weight estimated aboveground plant biomass in each plot. All emission rates are reported as actual, not normalized, emissions.

\section{Vegetation analysis and estimation of plant biomass}

The vegetation cover of vascular plants, mosses, lichens and litter was estimated in the plots subjected to ecosystem-level BVOC emission measurements and in 21 additional plots adjacent to biomass in the experimental plots, based on the point intercept data. $35 \times 35 \mathrm{~cm}$ frame with 25 fixed points ${ }^{34}$. In the additional plots, the vegetation was harvested, oven dried ( $60{ }^{\circ} \mathrm{C}$ for $72 \mathrm{hrs}$.) and weighed. For each species, linear regression was used to model the

\section{Ecosystem emission per gram plant biomass} the emission of non-terpenoid compounds was calculated per gram total plant biomass.

Isoprene emission was calculated per gram S. glauca present in each plot, monoterpene and sesquiterpene emission was calculated per gram biomass of all vascular plants except $S$. glauca and

\section{Q10-value for ecosystem emission}


Q10 was calculated using the following formula:

$Q 10={\frac{E_{W}}{E_{C}}}^{10 /\left(T_{W}-T_{C}\right)}$

where $E_{W}$ is the average ecosystem BVOC emission rate in the warmed plots and $E c$ is the average ecosystem BVOC emission rate in the controls. $T_{W}$ is the average temperature inside the enclosures in the warmed plots and $T_{C}$ is the average temperature inside the enclosures in the controls.

\section{Background data}

In each plot, soil temperature at 3-5 $\mathrm{cm}$ depth was monitored every hour using M-Log 5W Wireless Temperature Data Loggers (Geoprecision, Ettlingen, Germany). Soil moisture was measured once a week during the entire growing season.

Net ecosystem exchange, ecosystem respiration and soil respiration were measured weekly with a LI-6400XT portable gas-analyzer (LI-COR, Biosciences, Lincoln, USA; see Haugwitz et al. paper in preparation). The concentrations of dissolved organic nitrogen, ammonium, nitrate and phosphate in the soil were determined in $\mathrm{ddH}_{2} \mathrm{O}$-extracts of fresh soil using spectrophotometry (see Haugwitz et al. paper in preparation). Dissolved organic carbon (DOC) was analyzed with a Shimadzu TOC-L $\mathrm{CSH} / \mathrm{CSN}^{\mathrm{TM}}$ total organic carbon analyzer (Shimadzu, Kyoto, Japan), and microbial biomass was estimated from the difference in the DOC concentration in the chloroform-fumigated and non-

396 fumigated samples ${ }^{35}$. DNA was extracted from freeze-dried soil using FastDNA ${ }^{\mathrm{TM}}$ Spin Kit for Soil, 397 and subsequently quantitative polymerase chain reaction was performed targeting ITS2 region and 398 16S rDNA to estimate the fungal and bacterial abundance in the soil (see Haugwitz et al. paper in 399 preparation).

\section{Statistical tests}


The treatment effects on BVOC emissions in repeated measurements were tested by a linear mixed model in SAS 9.2. including Treatment (three levels: Control, W and RS) and Time as fixed factors 404 and Block as a random factor. Interactions with $p$-values $>0.2$ were stepwise removed from the model. One-way ANOVA was used to test for treatment effects within each measurement and for growing season averages. A Dunnett's test was used as a post hoc test to compare each treatment to 407 the control. The effects of biological and environmental factors on the ecosystem-level isoprene 408 emission were assessed by the PLS analysis. The tested variables, measured in the same plot, 409 included enclosure temperature, soil temperature, soil moisture, PAR, S. glauca biomass and E. 410 hermaphroditum biomass described in the present study and net ecosystem exchange, ecosystem 411 respiration, soil respiration, microbial biomass, fungal and bacterial abundance, nitrate, ammonium, 412 phosphate, soil organic matter, dissolved organic carbon and dissolved organic nitrogen (see 413 Haugwitz et al. paper in preparation). The PLS was performed with a cross-validation with six 414 segments in a Venetian blinds according to isoprene emission. In order to estimate the uncertainty 415 in the regression coefficients of each of the factors a resampling scheme - bootstrapping ${ }^{36}$ - was 416 performed 1000 times. One component PLS models were used throughout the analysis, and the 417 standard error was calculated as given in Wehrens et al. (ref. 36). 
13. Valolahti, H., Kivimäenpää, M., Faubert, P., Michelsen, A. \& Rinnan, R. Climate changeinduced vegetation change as a driver of increased subarctic biogenic volatile organic compound emissions. Glob. Change Biol. n/a (2015). doi:10.1111/gcb.12953

31. NERO 2008, Nuuk Ecological Research Operations, $1^{\text {st }}$ Annual Report, 2007 [Jensen, L. M. \& Rasch, M. (eds.) 2008] Copenhagen, Danish Polar Centre, Danish Agency for Science,

32. Tholl, D. et al. Practical approaches to plant volatile analysis. Plant J. 45, 540-560 (2006).

33. Ortega, J. et al. Approaches for quantifying reactive and low-volatility biogenic organic compound emissions by vegetation enclosure techniques - Part B: Applications. Chemosphere 72, 365-380 (2008).

34. Jonasson, S. Evaluation of the Point Intercept Method for the Estimation of Plant Biomass. Oikos 52, 101-106 (1988).

35. Jenkinson, D. S. \& Powlson, D. S. The effects of biocidal treatments on metabolism in soil434

36. Wehrens, R., Putter, H., Lutgarde, M. \& Buydens, C. The bootstrap: A tutorial. Chemometr. Intell. Lab. 54, 35-52 (2000). 